\title{
Assessment of addition of biochar to filtering mixtures for potential water pollutant removal
}

\author{
Lea Piscitelli ${ }^{1,2}$ - Pierre-Adrien Rivier ${ }^{2}$ - Donato Mondelli ${ }^{3}$ Teodoro Miano ${ }^{3}$. \\ Erik J. Joner ${ }^{2}$
}

Received: 8 February 2017 / Accepted: 31 October 2017 / Published online: 7 November 2017

(C) The Author(s) 2017. This article is an open access publication

\begin{abstract}
Green roofs are used increasingly to alleviate peaks of water discharge into the sewage systems in urban areas. Surface runoff from roofs contain pollutants from dry and wet deposition, and green roofs offer a possibility to reduce the amounts of pollutants in the water discharged from roofs by degradation and filtering. These pollutants would otherwise enter wastewater treatments plants and ultimately end up in sewage sludge that is spread on agricultural soils. The most common substrates used in green roofs have limited capacity for filtration and sorption. Also, more sustainable alternatives are sought, due to the high carbon footprint of these materials. Biochar is a carbon-rich material produced by pyrolysis of biomass, and several types of biochar have been described as good sorbents and filter materials. Biochar is also a light and carbon negative material, which may fulfill other desired criteria for new green roof substrates. We here report on an experiment where two types of biochar, produced from olive husks at $450{ }^{\circ} \mathrm{C}$ or from forest waste at $850^{\circ} \mathrm{C}$ were mixed with volcanic rock or peat, and tested for retention capacity of phenanthrene and six heavy metals in a column experiment with
\end{abstract}

Responsible editor: Philippe Garrigues

Electronic supplementary material The online version of this article (https://doi.org/10.1007/s11356-017-0650-6) contains supplementary material, which is available to authorized users.

Erik J. Joner

erik.joner@nibio.no

1 Mediterranean Agronomic Institute of Bari (CIHEAM), Via Ceglie, 9, Valenzano, 70010 Bari, Italy

2 Division of Environment and Natural Resources, Norwegian Institute of Bioeconomy Research, Høyskoleveien 7, 1431 Ås, Norway

3 Department of Food, Plants and Soil Science, University of Bari Aldo Moro, Via G. Amendola 165/a, 70126 Bari, Italy unsaturated gravimetric water flow lasting for 3 weeks. The results suggest that biochar as a component in green roof substrates perform better than traditional materials, concerning retention of the tested pollutants, and that different types of biochar have different properties in this respect.

Keywords Green roof substrates · Filtering mixtures · Biochar $\cdot$ Heavy metals $\cdot$ Phenanthrene $\cdot$ Column experiment

\section{Introduction}

Climate change is expected to cause increased frequency and intensity of rainfall, resulting in peaks of surface runoff from impermeable surfaces in urban areas. A strategy to mitigate urban flooding problems consists of retarding runoff using green roofs and similar flow-reducing installations. An additional environmental challenge comes from dissolved and particulate pollutants in precipitation and runoff from impermeable surfaces. These end up in sewage treatment plants and are ultimately discharged as sewage sludge into soils where they may transfer to plants and animals and the human food chain (Mench et al. 2009). In order to reduce the amount of contaminants that enter arable soil through this route, filtering and biodegradation in green roofs and other flow-reducing installations may become significant. The use of green roofs is increasing, and they are even considered an efficient and sustainable way to reduce the occurrence of pollutants in the environment (Dierkes et al. 2006). The pollutant removal capacity does however depend on the materials used and their inherent properties. At the same time, new roof materials are sought to reduce material costs and improve their overall environmental footprint. Currently used green roof materials feature, among others, volcanic rock and peat, which are light and inexpensive, but which are either exotic to large parts of the World, resulting 
in long-distance transport, or considered as non-sustainable due to negative climatic and environmental consequences of excavation and removal (Alexander et al. 2008).

Biochar can be produced by pyrolysis of any type of biomass and is a material characterized by a high porosity and a high-specific surface area. This porosity, along with a variety of both charged and hydrophobic surface micro sites, gives biochar favorable properties both for retaining water and for sorbing both ions and non-polar molecules. Biochar has positive effects on plants and is considered a good soil improver (Ennis et al. 2012). However, some variation for these properties is found between different types of biochar owing to differences of the parent biomass materials and pyrolysis conditions (Schimmelpfennig and Glaser 2011).

Heavy metal (HM) adsorption to biochar involves several types of interactions, including ion exchange, physical adsorption, electrostatic attraction, surface complexation, and precipitation and reduces their bioavailability and phytotoxicity (Park et al. 2011). On the other hand, the binding of organic contaminants to biochar often feature electrostatic interactions, hydrophobic effects, hydrogen bonds, and pore-filling (Ulrich et al. 2015).

Combining peat with biochar can result in a carbon neutral material due the carbon negative nature of biochar and its high resistance to degradation processes. Moreover, the high porosity and the large surface area of biochar can improve peat adsorption by ion exchange and surface complexation. In addition, the capacity of volcanic rock to retain water and remove contaminants can be improved by the addition of biochar, which potentially contributes to the increase of active sites and hydrophilic functional groups on the particle surface of the mixtures (Reddy et al. 2014).

Choice of feedstock and pyrolysis conditions makes it possible to enhance specific physiochemical properties of biochar (Verheijen et al. 2009). Thus, using biochars characterized by different properties regarding adsorption of pollutants could lead to desirable adsorption and filtering capacities. In order to evaluate the contribution of contrasting biochars for removing dissolved pollutants, each of two types of biochar (produced from olive husks or forest waste), were tested in a static batch incubation experiment and then in a dynamic column experiment.

The aim of this study was to assess whether the conventional green roof materials peat and volcanic rock could be improved regarding adsorption for heavy metals and phenanthrene (as a representative for organic contaminants with limited water solubility), when amended with either of two contrasting types of biochar. This was done by comparing key physico-chemical characteristics of the materials and mixtures, by measurements of the capacity to adsorb of the individual materials, and by assessing the filtering capacity of material mixtures during water percolation in a column experiment.

\section{Materials and methods}

\section{Experimental design}

A column experiment with four substrate combinations plus an overlaying sand layer spiked with phenanthrene (Phe) was set up with three replicate columns per treatment and percolated with an aqueous solution of heavy metals during three weekly episodes. Percolating water was recovered and analyzed to determine the capacity of the substrate mixtures to retain environmental pollutants. The four substrate combinations contained either $70 \%$ peat or $70 \%$ volcanic rock in combination with $30 \%$ of either of two types of biochar $(v / v)(30 \%$ is the maximum amount permitted for use in roof constructions according to risks of fire).

\section{Materials}

Peat (fibrous and only weakly transformed, limed to $\mathrm{pH}$ 6.5) was purchased from Nittedal Torvindustri AS (Arneberg, Norway) and volcanic rock (VR) from Veg Tech (Stockholm, Sweden). Wood biochar (BP), produced from mixed forest waste at $850^{\circ} \mathrm{C}$ by slow pyrolysis was purchased from Pyreg GmbH (Dörth, Germany). Olive husk biochar (BO) was produced by slow pyrolysis in an experimental reactor at $450{ }^{\circ} \mathrm{C}$ using air-dried olive husks by the Mediterranean Agronomic Institute of Bari (Valenzano, Bari, Italy). Some additional data about $\mathrm{BO}$ and $\mathrm{BP}$ are reported in Table $\mathrm{S} 1$ in supplementary information.

Prior to use, all materials were wet-sieved and the fraction between 1 and $2 \mathrm{~mm}$ retained, ensuring homogeneous particle distribution and avoiding particle-bound transport of the added contaminants.

The treatments obtained in this way were named peat/BP, peat/BO, VR/BP, and VR/BO from their constituents.

\section{Materials characterization}

Over-dried materials $\left(105^{\circ} \mathrm{C}\right)$ were characterized with respect to $\mathrm{pH}$ (sample to water ratio of $1: 2.5, w / v$ ), Eh, bulk density, and water holding capacity (WHC). The latter involved packing materials in volumetric cylinders with porous bottoms, soaking in water overnight, draining for $24 \mathrm{~h}$ on a saturated sandy surface, and measuring the retained water at $10-\mathrm{cm}$ height gravimetrically.

\section{Static adsorption}

In order to verify that metal concentrations to be used in a dynamic system were suitable, a batch adsorption experiment was conducted. Individual materials were thus assessed using aqueous solutions of metal ions and Phe at three different concentrations. Phenanthrene $\left(1.6 \mathrm{mg} \mathrm{l}^{-1}\right)$ and $5 \mathrm{mg} \mathrm{l}^{-1}$ of 
each of $\mathrm{Cd}\left(\mathrm{CdSO}_{4}\right), \mathrm{Cu}\left(\mathrm{CuSO}_{4}\right), \mathrm{Cr}\left(\mathrm{K}_{2} \mathrm{CrO}_{4}\right), \mathrm{Ni}\left(\mathrm{NiCl}_{2}\right)$, $\mathrm{Pb}\left(\mathrm{PbCl}_{2}\right)$, and $\mathrm{Zn}\left(\mathrm{ZnSO}_{4}\right)$ were used undiluted (high loading; $[\mathrm{H}]$ ) or diluted 1:1 (medium; [M]) or 1:10 (low; [L]). Three grams (d.wt.) of each substrate were placed in $100 \mathrm{ml}$ flasks and incubated in triplicate for $16 \mathrm{~h}$ at $23{ }^{\circ} \mathrm{C}$ with $60 \mathrm{ml}$ $(1,20, \mathrm{w}, \mathrm{v})$ of the three solutions $([\mathrm{H}],[\mathrm{M}]$, and $[\mathrm{L}])$ prior to analyzing the remaining unabsorbed pollutants. The extraction of the unabsorbed Phe was made by loading $20 \mathrm{ml}$ of the solutions on Bond Elut Plexa cartridges followed by elution with dichloromethane-ethyl acetate $(6,4)$ and analysis by gas chromatography-mass spectrometer (GC-MS) (Agilent 6890) using a HP-5MSi column (Agilent 19091S-433). The MS detection was carried out in SIM mode with a mass-tocharge ratio of 152.00. For metal analyses the incubated solutions were filtered using Whatman grade 1 paper filters and acidified with $\mathrm{HCl}$ before analysis by Induced Coupled Plasma-Optical Emission Spectroscopy (ICP-OES) (ICAP 6300, Thermo Electron, UK).

Control treatments, containing $3 \mathrm{~g}$ of each material and $60 \mathrm{ml}$ of water, were included and analyzed to account for metals and phenanthrene in the materials and from secondary pollution (see Table S2).

\section{Column experiment}

A column experiment was performed in order to explore the capacity for removal of pollutants in a dynamic system, comparing the performances of the four mixtures to the two traditional roof materials. Stainless-steel columns (10 cm diam.) with steel mesh bottoms fitted with filter paper to retain particles were filled with either of the four material mixtures to a height of $20 \mathrm{~cm}\left(1570 \mathrm{~cm}^{3}\right)$, and topped with a 2-cm layer of sand. Before the addition of the sand layer, columns containing the materials/material mixtures were percolated with $300 \mathrm{ml}$ of pure water in order to equilibrate the system and to verify the absence of pollutants in the percolated water. This sand had been spiked with Phe by adding $10 \mathrm{ml}$ of acetone containing $200 \mathrm{mg}$ Phe $\mathrm{L}^{-1}$ to each portion of $250 \mathrm{~g}$ of sand to reach a final concentration of $8 \mathrm{mg} \mathrm{kg}^{-1}$ of Phe. The spiked sand layer also ensured a uniform solution flow in the underlying material, while at the same time continuously releasing Phe through elution by the percolating water. A control treatment containing only Phe-spiked sand was included to verify the elution of Phe during percolation with water. At three occasions (day 7 , day 14 , and day 21 ), fixed volumes $(300 \mathrm{ml})$ of metal-spiked solution $\left(5 \mathrm{mg} \mathrm{l}^{-1}\right.$, same as used in the static experiment "Static adsorption") prepared for each individual column was pumped onto the sand layer and throughout the substrates using a peristaltic pump with a flow rate at approx. $1 \mathrm{ml} \mathrm{min}^{-1}$.

\section{Statistical analysis}

All data were statistically analyzed using one-way analysis of variance (ANOVA) and SPSS software. Means were compared by using the least significant difference test (LSD test) at $p<0.05$.

\section{Results and discussion}

\section{Material characteristics}

As shown in Table 1, the $\mathrm{pH}$ of the two biochars was alkaline, but not significantly different, whereas VR had a less alkaline $\mathrm{pH}$. The commercial peat contained some lime and had a slightly acidic $\mathrm{pH}$. Steiner and Harttung (2014) reported that peat could be mixed with up to $80 \%$ of biochar without raising the $\mathrm{pH}$ above 7 . In our study, both peat-based mixtures gave increased $\mathrm{pH}$ compared to pure peat when amended with $30 \%$ of biochar. All the analyzed mixtures had a $\mathrm{pH}$ in the optimal range for retention of heavy metals, yet not as high as to impede microbial activity and plant growth, or functioning as a filter material. Materials and mixtures proposed for this study had a low bulk density, which both facilitate transportation and handling, reduces the need for enhanced carrying capacity of roof constructions, and reduces the onset of clogging problems (Spychala and Ejewski 2003). Except VR, the materials and mixtures had a high WHC, which would also increase water retention time and provide suitable conditions for plant growth. An increased retention time of a green roof substrate results in both reduced peak roof out-flow and enhanced offset of water reaching the sewage system, and potentially increase pollutant adsorption on

Table 1 Characteristics of materials and mixtures. VR volcanic rock, BP biochar from wood, BO biochar from olive husks, WHC water holding capacity

\begin{tabular}{|c|c|c|c|c|c|c|c|c|c|}
\hline & & VR & BP & $\mathrm{BO}$ & Peat & VR/BP & VR/BO & Peat/BP & Peat/BO \\
\hline $\mathrm{pH}_{\text {water }}$ & $1: 2.5$ & 7.8 & 9.5 & 9.7 & 5.8 & 8.5 & 8.7 & 7.2 & 7.9 \\
\hline Density & $\mathrm{g} / \mathrm{cm}^{3}$ & 0.5 & 0.2 & 0.4 & 0.3 & 0.3 & 0.5 & 0.3 & 0.4 \\
\hline WHC & $\%$ & 42 & 258 & 73 & 149 & 112 & 54 & 205 & 143 \\
\hline
\end{tabular}




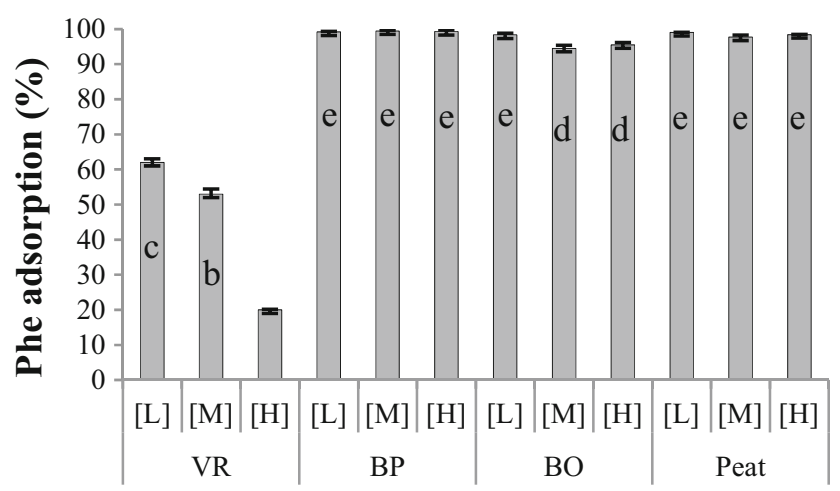

Fig. 1 Phenanthrene (Phe) adsorption of individual materials at different concentration (high loading; $[\mathrm{H}]$ ), diluted 1:1 (medium; $[\mathrm{M}]$ ), or 1:10 (low; [L]). Different letters above bars indicate significant difference between means $(p<0.05$, LSD test, $n=3)$

the substrate, as increased contact time allows for higher absorption of pollutants (Dalahmeh et al. 2012).
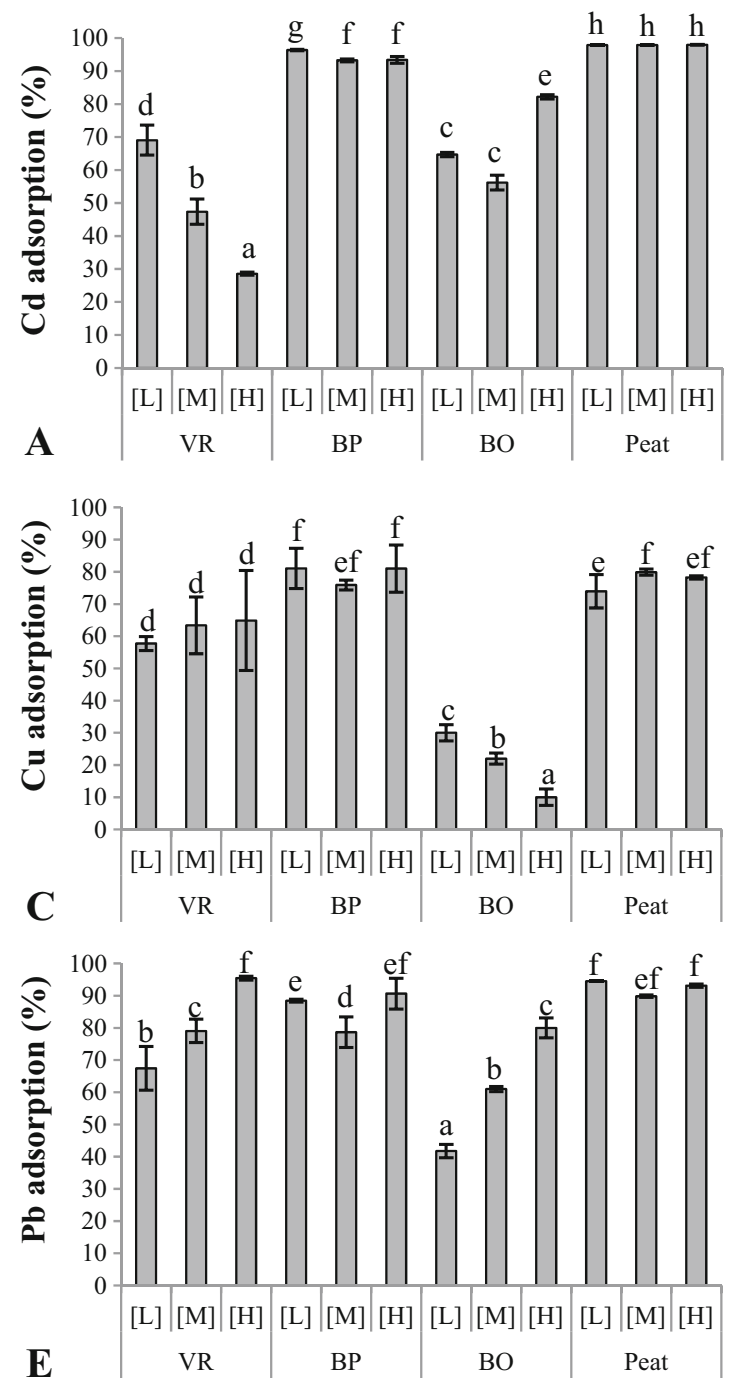

\section{Static retention capacity}

As shown in Fig. 1, VR had the lowest capacity in terms of Phe adsorption under static conditions and only retained 20 $60 \%$ of the Phe, the lowest values observed at high Phe loading rates. Phe adsorption for the other materials was high and indicated high affinities for Phe. The Phe absorption efficiency was not significantly different among the materials BP, BO, and Peat.

For metal adsorption, most of the tested materials displayed a reduced capacity to adsorb at increasing metal concentrations, and the simultaneous presence of six metal ions likely led to competition for the same binding sites (Kalmykova et al. 2008, Trakal et al. 2011). Figure 2 shows that BP and peat performed best regarding adsorption of $\mathrm{Cd}, \mathrm{Cu}, \mathrm{Ni}, \mathrm{Pb}$, and $\mathrm{Zn}$ under static conditions. $\mathrm{BO}$ had a higher adsorption than VR for $\mathrm{Cd}$ and $\mathrm{Ni}$, but lower absorption capacity for $\mathrm{Pb}$ and $\mathrm{Cu}$. The adsorption performance of $\mathrm{BO}$ and $\mathrm{VR}$ varied the
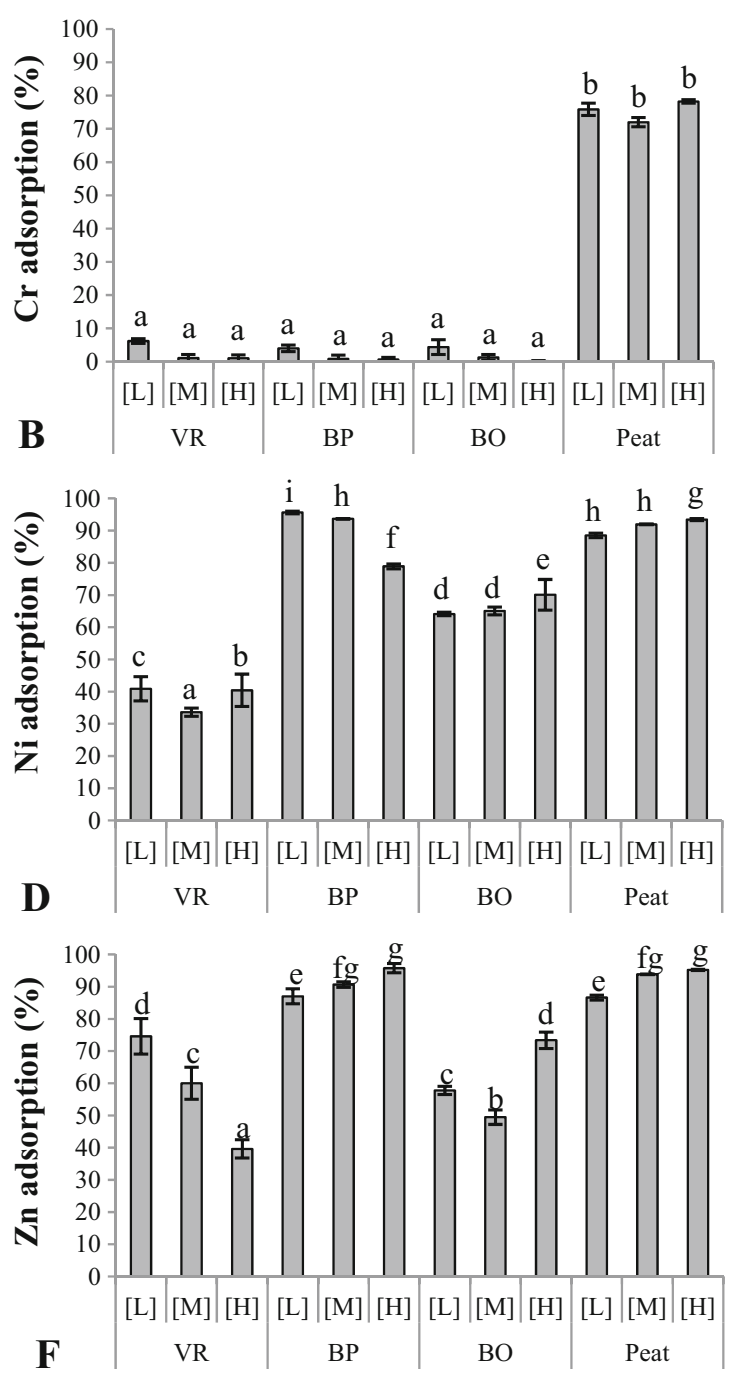

Fig. 2 Capacity of individual materials for adsorption of heavy metals (a: $\mathrm{Cd}, \mathbf{b}: \mathrm{Cr}, \mathbf{c}: \mathrm{Cu}, \mathbf{d}: \mathrm{Ni}, \mathbf{e}: \mathrm{Pb}, \mathbf{f}: \mathrm{Zn})$ at different concentration (high loading; $[\mathrm{H}]$ ), diluted 1:1 (medium; [M]), or 1:10 (low; [L]). Different letters above bars indicate significant difference between means $(p<0.05$, LSD test, $n=3$ ) 
most as a function of solution concentrations, with BO having the highest absorption capacity at the highest metal load for four metals. Peat performed well in terms of $\mathrm{Cr}$ adsorption, whereas all the other materials adsorbed little Cr. Several studies demonstrate that $\mathrm{Cr}$ adsorption efficiency increases with decreasing pH (Pandey et al. 2010, Ajouyed et al. 2011), a likely explanation for the higher adsorption of $\mathrm{Cr}$ of peat.

\section{Dynamic retention capacity}

Percolation through peat did not affect $\mathrm{pH}$ of the percolating solution, whereas the other materials and mixtures enhanced $\mathrm{pH}$ of the percolate. Metal-spiked solutions behaved similarly to pure water regarding changes in $\mathrm{pH}$ during percolation. Similarly, only peat maintained the initial high positive Eh of percolates $(41.0 \mathrm{mV})$, while the other materials and mixtures reduced Eh. Low Eh may potentially affect $\mathrm{Cr}$ speciation, though reduced $\mathrm{Eh}$ and increasing $\mathrm{pH}$ act in opposite directions as to conserve initial $\mathrm{Cr}$ species, though on a longer term, $\mathrm{Cr}$ may be reduced in such a system (Kotaś and Stasicka 2000). No significant variation in Eh was observed between water used for conditioning columns and metal-spiked solutions used for the three percolations. Results related to $\mathrm{pH}$ and
Eh variations within treatments after conditioning and during the percolations are presented in Fig. S1.

All materials and mixtures showed high retention of Phe, removing more than $94 \%$, even after the third percolation event at the 21st day (Table 2). The VR/BO mixture had a lasting retention efficiency trend, probably due to a complementary in composition of hydrophobic binding sites. VR is not likely to affect the surface functional groups of biochar or clog its pores, due to its lack of soluble organic constituents. The peat/BO mixture removed relatively little of the Phe, possibly due to the interaction of the two materials which could mutually block or reduce the availability of adsorption sites.

At day 21, the different adsorption behaviors of peat versus peat/BP, and of VR versus VR/BP, clearly indicated the role of $\mathrm{BP}$ in increasing the retention capacity of the mixtures. Still, both the mixtures containing BP only resulted in short-term Phe retention, probably due to adsorption by relatively weak physical bonds. The surface of biochar is highly heterogeneous due to the co-existence of carbonized and noncarbonized parts, which provide several adsorption possibilities for organic pollutants (Chen et al. 2008; Cao et al. 2009; Zheng et al. 2010). Moreover, biochar is characterized by an extended micro-porosity and a high surface area, properties specifically related to the adsorption of PAHs (Yu et al. 2009,

Table 2 Phenanthrene and metal removal capacity (\%) of materials and mixtures during three repeated (7, 14, 21 days) percolations. Material abbreviations as in Table 1. Within each percolation event, significant difference between treatments for individual compounds are indicated by different letters $(p<0.05$, LSD test, $n=3$, means $\pm \mathrm{SD})$

\begin{tabular}{|c|c|c|c|c|c|c|c|c|c|c|c|c|c|}
\hline & Time & VR & & $\mathrm{VR} / \mathrm{BP}$ & & $\mathrm{VR} / \mathrm{BO}$ & & Peat & & Peat/BP & & Peat/BO & \\
\hline & (days) & & & & & & & & & & & & \\
\hline & 7 & $95 \pm 1.1$ & $\mathrm{~d}$ & $98 \pm 1.0$ & $a b c$ & $99 \pm 0.8$ & $\mathrm{a}$ & $99 \pm 0.6$ & $a b$ & $99 \pm 0.5$ & $\mathrm{~b}$ & $96 \pm 2.0$ & $\mathrm{c}$ \\
\hline \multirow[t]{3}{*}{ Phe } & 14 & $99 \pm 0.1$ & $\mathrm{k}$ & $98 \pm 0.5$ & 1 & $98 \pm 0.7$ & 1 & $99 \pm 0.4$ & $\mathrm{k}$ & $99 \pm 0.2$ & $\mathrm{k}$ & $99 \pm 0.3$ & $\mathrm{k}$ \\
\hline & 21 & $94 \pm 1.6$ & $\mathrm{y}$ & $95 \pm 1.5$ & xy & $99 \pm 0.0$ & $\mathrm{w}$ & $98 \pm 1.1$ & $\mathrm{w}$ & $96 \pm 1.3$ & $\mathrm{x}$ & $98 \pm 0.9$ & wx \\
\hline & 7 & $100 \pm 0.0$ & & $100 \pm 0.0$ & & $100 \pm 0.0$ & & $100 \pm 0.0$ & & $100 \pm 0.0$ & & $100 \pm 0.0$ & \\
\hline \multirow[t]{3}{*}{$\mathrm{Cd}$} & 14 & $100 \pm 0.2$ & & $100 \pm 0.0$ & & $100 \pm 0.0$ & & $100 \pm 0.0$ & & $100 \pm 0.0$ & & $100 \pm 0.0$ & \\
\hline & 21 & $100 \pm 0.2$ & & $100 \pm 0.1$ & & $100 \pm 0.0$ & & $100 \pm 0.1$ & & $100 \pm 0.0$ & & $100 \pm 0.0$ & \\
\hline & 7 & $80 \pm 4.1$ & $\mathrm{c}$ & $82 \pm 2.8$ & $\mathrm{c}$ & $69 \pm 5.2$ & $\mathrm{~d}$ & $99 \pm 0.5$ & $\mathrm{a}$ & $91 \pm 2.8$ & $\mathrm{~b}$ & $89 \pm 3.9$ & $\mathrm{~b}$ \\
\hline \multirow[t]{3}{*}{$\mathrm{Cr}$} & 14 & $57 \pm 6.7$ & $\mathrm{~m}$ & $56 \pm 0.5$ & $\mathrm{~m}$ & $44 \pm 5.1$ & $\mathrm{n}$ & $100 \pm 0.5$ & $\mathrm{k}$ & $90 \pm 3.3$ & 1 & $88 \pm 5.9$ & 1 \\
\hline & 21 & $40 \pm 3.0$ & $\mathrm{y}$ & $36 \pm 2.4$ & $\mathrm{y}$ & $29 \pm 6.6$ & $\mathrm{z}$ & $98 \pm 1.5$ & $\mathrm{w}$ & $90 \pm 3.2$ & $\mathrm{x}$ & $85 \pm 5.2$ & $\mathrm{x}$ \\
\hline & 7 & $97 \pm 0.1$ & $\mathrm{c}$ & $98 \pm 0.2$ & $\mathrm{~b}$ & $99 \pm 0.3$ & $\mathrm{a}$ & $99 \pm 0.6$ & $\mathrm{a}$ & $99 \pm 0.3$ & $\mathrm{a}$ & $99 \pm 0.1$ & $\mathrm{a}$ \\
\hline \multirow[t]{3}{*}{$\mathrm{Cu}$} & 14 & $98 \pm 0.4$ & 1 & $99 \pm 0.2$ & $\mathrm{k}$ & $100 \pm 0.1$ & $\mathrm{k}$ & $99 \pm 0.3$ & $\mathrm{k}$ & $99 \pm 0.2$ & $\mathrm{k}$ & $99 \pm 0.1$ & $\mathrm{k}$ \\
\hline & 21 & $99 \pm 0.1$ & $\mathrm{x}$ & $100 \pm 0.1$ & $\mathrm{w}$ & $98 \pm 0.5$ & $\mathrm{y}$ & $99 \pm 0.1$ & $\mathrm{x}$ & $100 \pm 0.1$ & $\mathrm{w}$ & $100 \pm 0.1$ & $\mathrm{w}$ \\
\hline & 7 & $98 \pm 0.1$ & $\mathrm{c}$ & $97 \pm 0.2$ & $\mathrm{c}$ & $98 \pm 0.7$ & $\mathrm{~b}$ & $99 \pm 0.2$ & $\mathrm{a}$ & $99 \pm 0.4$ & $a b$ & $99 \pm 0.8$ & $\mathrm{ab}$ \\
\hline \multirow[t]{3}{*}{$\mathrm{Ni}$} & 14 & $98 \pm 0.6$ & $\mathrm{~m}$ & $98 \pm 0.5$ & $\mathrm{~m}$ & $99 \pm 0.3$ & 1 & $100 \pm 0.1$ & $\mathrm{k}$ & $99 \pm 0.8$ & 1 & $99 \pm 0.1$ & 1 \\
\hline & 21 & $98 \pm 0.5$ & $\mathrm{x}$ & $99 \pm 0.3$ & $\mathrm{w}$ & $99 \pm 0.2$ & $\mathrm{w}$ & $99 \pm 0.3$ & $\mathrm{w}$ & $99 \pm 0.2$ & $\mathrm{w}$ & $100 \pm 0.0$ & $\mathrm{w}$ \\
\hline & 7 & $100 \pm 0.1$ & $\mathrm{a}$ & $99 \pm 0.1$ & $\mathrm{~b}$ & $100 \pm 0.2$ & $\mathrm{a}$ & $98 \pm 0.5$ & $\mathrm{c}$ & $99 \pm 0.1$ & $\mathrm{~b}$ & $98 \pm 0.5$ & $\mathrm{c}$ \\
\hline \multirow[t]{3}{*}{$\mathrm{Pb}$} & 14 & $100 \pm 0.0$ & $\mathrm{k}$ & $99 \pm 0.2$ & 1 & $100 \pm 0.1$ & $\mathrm{k}$ & $98 \pm 0.5$ & $\mathrm{~m}$ & $99 \pm 0.2$ & 1 & $99 \pm 0.2$ & 1 \\
\hline & 21 & $100 \pm 0.2$ & $\mathrm{w}$ & $100 \pm 0.2$ & $\mathrm{w}$ & $100 \pm 0.1$ & $\mathrm{w}$ & $98 \pm 0.5$ & $\mathrm{y}$ & $99 \pm 0.1$ & $\mathrm{x}$ & $99 \pm 0.1$ & $\mathrm{x}$ \\
\hline & 7 & $99 \pm 0.1$ & $\mathrm{~b}$ & $99 \pm 0.1$ & $\mathrm{~b}$ & $100 \pm 0.1$ & $\mathrm{a}$ & $96 \pm 0.5$ & $\mathrm{~d}$ & $98 \pm 0.2$ & $\mathrm{c}$ & $98 \pm 0.6$ & $\mathrm{c}$ \\
\hline \multirow[t]{2}{*}{$\mathrm{Zn}$} & 14 & $100 \pm 0.1$ & $\mathrm{k}$ & $99 \pm 0.2$ & 1 & $100 \pm 0.1$ & $\mathrm{k}$ & $98 \pm 0.5$ & $\mathrm{n}$ & $99 \pm 0.2$ & $\mathrm{~m}$ & $99 \pm 0.2$ & $\mathrm{~m}$ \\
\hline & 21 & $100 \pm 0.1$ & $\mathrm{w}$ & $100 \pm 0.2$ & $\mathrm{w}$ & $100 \pm 0.1$ & $\mathrm{w}$ & $98 \pm 0.5$ & $\mathrm{y}$ & $99 \pm 0.1$ & $\mathrm{x}$ & $99 \pm 0.1$ & $\mathrm{x}$ \\
\hline
\end{tabular}


Yang et al. 2010, Lou et al. 2011). Generally speaking, biochar obtained by low-temperature processes are typically characterized by higher surface area, increased micro-pore distribution, and a higher non-carbonized fraction compared to biochar produced at higher temperatures (Novotny et al. 2015). The superior performance of $\mathrm{BO}$ for removal of Phe after repeated infiltration may be explained by this difference in production (Uchimiya et al. 2010, Yang et al. 2010, Ahmad et al. 2012, Chen et al. 2008).

All material mixtures performed well regarding retention of $\mathrm{Cd}$ from percolating water (Table 2), and no significant differences were observed between treatments. For $\mathrm{Cr}$ adsorption, peat (alone or in mixtures) had the highest retention capacity and a stable performance over the three percolation events. No significant differences were observed between the other material mixtures over 21 days. According to Balan et al. (2009), lignin, cellulose, and hemicelluloses have crucial roles in sorption-coupled reduction removal processes. Moreover, several studies argue that biochar removes $\mathrm{Cr}$ via a preliminary electrostatic attraction, reduction to $\mathrm{Cr}$ (III), and subsequent complexation via $\mathrm{O}$-containing functional groups (Dong et al. 2011, Choppala et al. 2012, and Bolan et al. 2013). These two mechanisms were probably active and persisted in peat/BP and peat/BO mixtures and were enhanced by the presence of peat.

Volcanic rock had a very low capacity for retention of $\mathrm{Cu}$ compared to the other materials, but mixing VR and biochar improved the retention capacity. Compared to other divalent metals, $\mathrm{Cu}$ has the highest affinity for carboxylic functional groups (Tong et al. 2011). Lima et al. (2010) reported that metal adsorption was higher for washed biochar than for untreated biochar due to an improved accessibility of their functional groups. Based on the features reported by these two studies, the enhanced $\mathrm{Cu}$ retention could be explained as an additive effect of these interactions. Specifically, the preferential formation of surface complexes between $\mathrm{Cu}$ and biochar functional groups can lead to exchange phenomena with other divalent metals previously adsorbed onto the mixtures, which may increase with time.

Nickel adsorption onto solid materials is most efficient in a pH range between 8 and 9 (Bartczak et al. 2015, Zhang and Wang 2015). Still, as shown in Table 2, peat retained almost all Ni entering the system. Moreover, peat had the highest and most persisting Ni removal capacity of the materials tested. The high retention capacity of peat/BO and peat/BP, and the increasing retention of VR-treatments, shows additive effects, possibly through increasing access to functional groups or binding sites.

For Pb, VR treatments had higher retention capacity than peat-containing mixtures. Malakootian et al. (2009) report that VR is capable of retaining large amounts of $\mathrm{Pb}$ due to its alkaline $\mathrm{pH}$. This can also explain the increased retention capacity of $\mathrm{Pb}$ observed for peat when mixed with biochar. $\mathrm{Lu}$ et al. (2012) showed that $\mathrm{Pb}$ adsorption on biochar mainly occurs by outer-sphere exchange phenomena with other cations $(\mathrm{Ca}, \mathrm{K}, \mathrm{Mg})$ that are commonly available on biochar surface. Moreover, for VR/BO and VR/BP, ion exchange mechanisms can easily have occurred due to the weak retention of VR compared to peat.

Table 2 shows Zn removal capacities, where VR adsorbed more $\mathrm{Zn}$ as compared to peat. Generally, adsorption processes occur through joint chemical and physical mechanisms (Tan et al. 2015). Sen and Khoo (2013) reported that the adsorption of $\mathrm{Zn}$ on clay surface occurs in two steps: a rapid adsorption of metal ions to the external surface, followed by possible slow diffusion towards the inner surfaces of the pores. The biochar samples used in this study showed both chemical and physical adsorption mechanisms that would contribute to the latter adsorption mechanism leading to high $\mathrm{Zn}$ removal in mixtures.

\section{Conclusion}

A good green roof material must be light, highly porous, and resistant to water erosion. It should not be prone to clogging and provide an appropriate water retention/ release performance. Both VR, peat, and their mixtures with biochar perform well regarding density and through the flow of water. For the retention of environmental pollutants, green roof materials should also allow a high mass transfer and be selective for pollutants of high concern. Here, the four materials used performed differently for different pollutants, and mixtures were clearly superior when the combined retention of all the tested pollutants are considered. This, along with the additional environmental benefits from using biochar from local and recycled materials, makes mixed green roof substrates containing biochar promising alternatives to present day's use of less sustainable materials. The additional possibility to grow plants that support intensive use is another advantage of biochar mixtures (Cao et al. 2014, Nemati et al. 2014). The mixtures generally show improved retention behavior compared to pure materials. Their inclusion in roofs constructed with traditional roof materials will thus improve filtering performances, both quantitatively and qualitatively. Moreover, our study suggests that roof material mixtures can be designed using different types of biochar to facilitate retention of specific contaminants that cause problems locally.

Acknowledgements The authors thank the International Humic Substances Society (IHSS) for providing financial support to young scientist through IHSS-Training Awards, which allowed them to pursue this research work. Moreover, they thank Hans Ragnar Norli (NIBIO) for the help with extractions and performing GC-MS analyses, and Jan-Erik Jacobsen (NIBIO) for ICP analyses. 
Open Access This article is distributed under the terms of the Creative Commons Attribution 4.0 International License (http:// creativecommons.org/licenses/by/4.0/), which permits unrestricted use, distribution, and reproduction in any medium, provided you give appropriate credit to the original author(s) and the source, provide a link to the Creative Commons license, and indicate if changes were made.

\section{References}

Ahmad M, Lee SS, Dou X, Mohan D, Sung JK, Yang JE, Ok YS (2012) Effects of pyrolysis temperature on soybean stover- and peanut shell-derived biochar properties and TCE adsorption in water. Bioresour Technol 118:536-544. https://doi.org/10.1016/j.biortech. 2012.05.042

Ajouyed O, Hurel C, Marmier N (2011) Evaluation of the adsorption of hexavalent chromium on kaolinite and illite. J E P 2:1347-1352. https://doi.org/10.4236/jep.2011.210155

Alexander PD, Bragg NC, Meade R, Padelopoulos G, Watts O (2008) Peat in horticulture and conservation: the UK response to a changing world. Mires Peat 3:1-10 ISSN 1819-754X

Balan C, Bilba D, Macoveanu M (2009) Sphagnum moss peat as a potential sorbent and reduction for Chromium (VI) removal from acqueous solutions. Cellul Chem Technol 43:99-104

Bartczak P, Norman M, Klapiszewski L, Karwanska N, Kawalec M, Baczynska M, Wysokowski M, Zdarta J, Ciesielczyk F, Jesionowski $\mathrm{T}$ (2015) Removal of $\mathrm{Ni}$ (II) ions from aqueous solution using peat as a low cost adsorbent: a kinetic and equilibrium study. Arab J Chem. https://doi.org/10.1016/j.arabjc.2015.07.018

Bolan NS, Choppala G, Kunhikrishnan A, Park JH, Naidu R (2013) Microbial transformation of trace elements in soils in relation to bioavailability and remediation. Arch Environ Contam Toxicol 225:1-56. https://doi.org/10.1007/978-1-4614-6470-9 1

Cao XD, Ma L, Gao B, Harris W (2009) Dairy-manure derived biochar effectively sorbs lead and atrazine. Environ Sci Technol 43:32853291. https://doi.org/10.1021/es803092k

Cao CTN, Farrell C, Kristiansen PE, Rayner JP (2014) Biochar makes green roof substrates lighter and improves water supply to plants. Ecol Eng 71:368-374. https://doi.org/10.1016/j.ecoleng.2014.06. 017

Chen B, Zhou D, Zhu L (2008) Transitional adsorption and partition on nonpolar and polar aromatic contaminants by biochars of pine needles with different pyrolytic temperatures. Environ Sci Technol 42:5137-5143. https://doi.org/10.1021/es8002684

Choppala GK, Bolan NS, Mallavarapu M, Chen Z, Naidu R (2012) The influence of biochar and black carbon on reduction and bioavailability of chromate in soils. J Environ Qual 41:1-10. https://doi.org/10. 2134/jeq2011.0145

Dalahmeh SS, Pell M, Vinneras B, Hylander LD, Oborn I, Jonsson H (2012) Efficiency of bark, activated charcoal, foam and sand filters in reducing pollutants from greywater. Water Air Soil Pollut 223:115. https://doi.org/10.1007/s11270-012-1139-z

Dierkes C, Gobel P, Lohmann M, Coldewey WG (2006) Development and investigation of a pollution control pit for treatment of stormwater from metal roofs and traffic areas. Water Sci Technol 54:291-298. https://doi.org/10.2166/wst.2006.597

Dong X, Ma LQ, Li Y (2011) Characteristics and mechanisms of hexavalent chromium removal by biochar from sugar beet tailing. J Hazard Mater 190:909-915. https://doi.org/10.1016/j.jhazmat. 2011.04.008

Ennis CJ, Evans AG, Islam M, Komang RT, Senior E (2012) Biochar: carbon sequestration, land remediation and impacts on soil microbiology. Crit Rev in Environ Sci Technol 42:2311-2364. https://doi. org/10.1080/10643389.2011.574115
Kalmykova Y, Strömvall AM, Steenari BM (2008) Alternative materials for adsorption of heavy metals and petroleum hydrocarbons from contaminated leachates. Environ Technol 29:111-122. https://doi. org/10.1080/09593330802009444

Kotaś J, Stasicka Z (2000) Chromium occurrence in the environment and methods of its speciation. Environ Pollut 107:263-283. https://doi. org/10.1016/S0269-7491(99)00168-2

Lima IM, Boateng AA, Klasson KT (2010) Physicochemical and adsorptive properties of fast-pyrolysis bio-chars and their steam activated counterparts. J Chem Technol Biotechnol 85:1515-1521. https:// doi.org/10.1002/jctb.2461

Lou L, Wu B, Wang L, Luo L, Xu X, Hou J, Xun B, Hu B, Chen Y (2011) Sorption and ecotoxicity of pentachlorophenol polluted sediment amended with rice-straw derived biochar. Bioresour Technol 102: 4036-4041. https://doi.org/10.1016/j.biortech.2010.12.010

Lu H, Zhang W, Yang Y, Huang X, Wang S, Qiu R (2012) Relative distribution of $\mathrm{Pb}^{2+}$ sorption mechanisms by sludge-derived biochar. Water Resour Res 46:854-862. https://doi.org/10.1016/j.watres. 2011.11.058

Mench M, Schwitzguebel J, Schroeder P, Bert V, Gawronski S, Gupta S (2009) Assessment of successful experiments and limitations of phytotechnologies: contaminant uptake, detoxification and sequestration, and consequences for food safety. Environ Sci Pollut Res 16: 876-900. https://doi.org/10.1007/s11356-009-0252-z

Malakootian M, Nouri J, Hossaini H (2009) Removal of heavy metals from paint industry's wastewater using Leca as an available adsorbent. Environ Sci Technol 6:183-190. https://doi.org/10.1007/ BF03327620

Nemati MR, Simard F, Fortin JP, Beaudoin J (2014) Potential use of biochar in growing media. Vadose Zone J 14:1-8. https://doi.org/ 10.2136/vzj2014.06.0074

Novotny EH, Branco de Freitas Maia CM, Thaís de Melo Carvalho M, Madari BE (2015) Biochar: pyrogenic carbon for agricultural usea critical review, better answer to this remark. Rev Bras Cienc Solo, 39:321-344. doi: https://doi.org/10.1590/01000683rbcs20140818

Pandey PK, Sharma SK, Sambi SS (2010) Kinetics and equilibrium study of chromium adsorption on zeolite Na X. Environ Sci Technol 7: 395-404. https://doi.org/10.1007/BF03326149

Park J, Choppala G, Bolan N, Chung J, Chuasavathi T (2011) Biochar reduces the bioavailability and phytotoxicity of heavy metals. Plant Soil 348:439-451. https://doi.org/10.1007/s11104-011-0948-y

Reddy KR, Xie T, Dastgheibi S (2014) Evaluation of biochar as a potential filter media for the removal of mixed contaminants from urban storm water runoff. J Environ Eng 140:40-43. https://doi.org/10. 1061/(ASCE)EE.1943-7870.0000872

Schimmelpfennig S, Glaser B (2011) One step forward toward characterization: some important material properties to distinguish biochars. J Environ Qual 41:1001-1013. https://doi.org/10.2134/jeq2011.0146

Sen TK, Khoo C (2013) Adsorption characteristics of zinc $\left(\mathrm{Zn}^{2+}\right)$ from aqueous solution by natural bentonite and kaolin clay minerals: a comparative study. Comp water energy. Environ Eng 2:1-6. https:// doi.org/10.4236/cweee.2013.23B001

Spychala M, Ejewski RB (2003) Sand filter clogging by septic tank effluent. Water Sci Technol 48:153-159

Steiner C, Harttung T (2014) Biochar as a growing media additive and peat substitute. Solid Earth 5:995-999. https://doi.org/10.5194/se-5995-2014

Tan X, Liu Y, Zeng G, Wang X, Hu X, Gu Y, Yang Z (2015) Application of biochar for the removal of pollutants from aqueous solutions. Chemosphere 125:70-85. https://doi.org/10.1016/j.chemosphere. 2014.12.058

Tong SJ, Li JY, Yuan JH, RK X (2011) Adsorption of Cu(II) by biochars generated from three crop straws. Chem Eng J 172:828-834. https:// doi.org/10.1016/j.cej.2011.06.069

Trakal L, Komárek M, Száková J, Zemanová V, Tlustoš P (2011) Biochar application to metal-contaminated soil: evaluating of $\mathrm{Cd}, \mathrm{Cu}, \mathrm{Pb}$ and 
$\mathrm{Zn}$ sorption behavior using single- and multi-element sorption experiment. Plant Soil Environ 57:372-380

Uchimiya M, Wartelle LH, Lima IM, Klasson KT (2010) Sorption of deisopropylatrazine on broiler litter biochars. J Agric Food Chem 58:50-56. https://doi.org/10.1021/jf102152q

Ulrich BA, Im EA, Werner D, Higgins CP (2015) Biochar and activated carbon for enhanced trace organic contaminant retention in stormwater infiltration systems. Environ Sci Technol 49:62226230. https://doi.org/10.1021/acs.est.5b00376

Verheijen FGA, Jeffery S, Bastos AC, van der Velde M, Diafas I (2009) Biochar application to soils - a critical scientific review of effects on soil properties, processes and functions. EUR 2409, Office for the Official Publications of the European Communities, Luxembourg

Yang XB, Ying GG, Peng PA, Wang L, Zhao JL, Zhang LJ, Yuan P, He HP (2010) Influence of biochars on plant uptake and dissipation of two pesticides in an agricultural soil. J Agric Food Chem 58:79157921. https://doi.org/10.1021/jf1011352

Yu XY, Ying GG, Kookana RS (2009) Reduced plant uptake of pesticides with biochar additions to soil. Chemosphere 76:665-671. https:// doi.org/10.1016/j.chemosphere.2009.04.001

Zhang X, Wang X (2015) Adsorption and desorption of nickel(II) ions from aqueous solution by a lignocellulose/montmorillonite nanocomposite. PLoS One 10:117-177. https://doi.org/10.1371/journal. pone. 0117077

Zheng W, Guo M, Chow T, Bennet DN, Rajagopalan N (2010) Sorption properties of greenwaste biochar for two triazine pesticides. J Hazard Mater 181:121-126. https://doi.org/10.1016/j.jhazmat. 2010.04.103 